\title{
Commentary More Time for Science and Less Time for Administration?
}

\author{
Charles B Nemeroff ${ }^{*}, 1,2$ and Natalie Rasgon ${ }^{2,3}$ \\ 'Department of Psychiatry and Behavioral Sciences, University of Miami Miller School of Medicine, Miami, Florida; ${ }^{2}$ The ACNP Liaison Committee; \\ ${ }^{3}$ Department of Psychiatry and Behavioral Sciences, Stanford University School of Medicine, Stanford, Califormia
}

Neuropsychopharmacology (2016) 4I, 2625-2626; doi: I0. I038/npp.2016.89; published online 13 July 2016

That is the question posed, among other cognate issues, by the Alexander-Murray Bill introduced by the leadership of the Senate Health Committee. In the midst of a raucous political season that can only be characterized as highly unusual, to say the least, this bipartisan duo has remarkably and insightfully targeted an increasing problem for the scientific community, namely the never ending and expanding administrative burden of conducting scientific research in the United States. Between the demands from each NIH Institute, and the Divisions within individual institutes, and a researcher's institution-often compounded by reports to both individual schools (eg, medicine or public health, and the university as a whole), individual entities within the university (eg, IRB, IACUC), not to mention, individual hospital systems (eg, Veterans Administration, university hospitals, community and county hospitals)-the labyrinthine nature of the requisite reporting is substantial. Add to these the frequent scheduled and random audits that require many hours of attention, and are often announced by frightening language that proclaim the power to shut down research programs for non-compliance, and one can begin to realize that this is far from an ideal situation in which the spirit of discovery can thrive. Both the bill's sponsor and the authors of this commentary recognize, of course, the need for rigorous oversight of scientific research-the paramount importance of strictly abiding to the protection of human and laboratory animal subjects in research, the need to be transparent about potential conflicts of interest, and to be vigilant about scientific misconduct. This administrative burden not only weighs heavily on current funded investigators but serves as a negative influence on junior investigators who, witnessing the dwindling research time of their senior colleagues, coupled with the difficult funding climate, are too easily dissuaded from moving forward in an academic career. In addition, the cost burden falls upon

\footnotetext{
*Correspondence: Dr C Nemeroff, Department of Psychiatry \& Behavioral Sciences, University of Miami, University of Miami Miller School of Medicine, I 120 NW I 4th Street, Room I 455 (D-2 I), Miami, 33136, Florida, USA, Tel: +305 243 6400, Fax: +305 243 8532, E-mail: cnemeroff@med.miami.edu

Received 20 May 2016; revised 24 May 2016; accepted 26 May 20 6; accepted article preview online 9 June 2016
}

taxpayers, who want their NIH to facilitate rapid-paced development of cures, but instead are seeing subtractions from what is available for research activities in the name of creating and maintaining new layers of oversight upon scientists.

If we then add the considerable administrative burden incurred in the conduct of clinical treatment trials that often includes oversight by the FDA in addition to NIH and other funding agencies, the burden becomes even more ominous.

The impetus for the bill was the result of two National Academies of Sciences reports, indicating that principal investigators spend a remarkably $42 \%$ of their effort on administrative tasks-a number of the reports' authors suggested to be a more appropriate $10 \%$. The bill calls for a marked streamlining of administrative requirements for both intramural NIH researchers and recipients of NIH grants.

A related issue, especially for the precious few of the clinician scientists in our field is the correspondingly large increase in administrative burden in providing direct clinical services to our patients. Although not included in this bill, the increasing burden for clinical documentations via the electronic medical record and the multitude of such platforms, and the requirement for many clinician scientists to be able to use many of these practice-based and hospitalbased tools is yet another administrative burden. Further administrative demands are placed on clinician scientists to maintain medical licensure and specialty board certification and recertification, as well as licenses for prescribing from the Drug Enforcement Agency. This is also required of basic scientists who use controlled substances in their animal research.

It is important to note that the bill contains a few other significant features. This includes a call to allow the National Center for Advancing Translational Sciences to support later phase clinical trials to more rapidly advance the development of novel treatments. There is also a clause in the bill to have all NIH institute directors evaluated and reappointed at 5 -year intervals. These suggested changes would be overseen by a board that would oversee the bill's implementationmembers consisting of $\mathrm{NIH}$ institute directors, the NIH director, and others from the academic community. We would hope that the university regulatory bodies would 
embrace this initiative and contribute to the reduction in administrative burden of investigators.

At a time of such polarization in the nation's capital, it is heartening to see a bipartisan bill to enable our scientific colleagues to focus on science and, as a result, be more productive. Who would disagree that, almost like motherhood, apple pie, and the flag, the spirit of scientific innovation should be admired and cherished?

Editor's Note: The text of a report providing the basis for the legislature described in this Commentary is available at www.nsf.gov/pubs/2014/nsb1418/nsb1418.pdf.

\section{FUNDING AND DISCLOSURE}

CBN discloses the following: Research/Grants: National Institutes of Health (NIH). Consulting (last three years): Xhale, Takeda, Mitsubishi Tanabe Pharma Development America, Taisho Pharmaceutical Inc., Lundbeck, Prismic Pharmaceuticals, Bracket (Clintara), Total Pain Solutions
(TPS), Gerson Lehrman Group (GLG) Healthcare \& Biomedical Council, Fortress Biotech, Sunovion Pharmaceuticals Inc., Stockholder: Xhale, Celgene, Seattle Genetics, Abbvie, Titan Pharmaceuticals, OPKO Health, Inc., Bracket Intermediate Holding Corp., Network Life Sciences Inc. Scientific Advisory Boards: American Foundation for Suicide Prevention (AFSP), Brain and Behavior Research Foundation (BBRF) (formerly named National Alliance for Research on Schizophrenia and Depression [NARSAD]), Xhale, Anxiety Disorders Association of America (ADAA), Skyland Trail, Bracket (Clintara), RiverMend Health LLC, Laureate Institute for Brain Research, Inc. Directorial Board: AFSP, Gratitude America, ADAA. Income sources or equity of $\$ 10,000$ or more: American Psychiatric Publishing, Xhale, Bracket (Clintara), CME Outfitters, Takeda. Patents: Method and devices for transdermal delivery of lithium (US $6,375,990 \mathrm{~B} 1)$. Method of assessing antidepressant drug therapy via transport inhibition of monoamine neurotransmitters by ex vivo assay (US 7,148,027B2). NR declares no conflict of interest. 